\title{
SOFTWARE ERGONOMICS: EFFECTS OF COMPUTER APPLICATION DESIGN PARAMETERS ON OPERATOR TASK PERFORMANCE AND HEALTH
}

\author{
Jon A. Turner \\ New York University \\ Robert A. Karasek, Jr. \\ Columbia University \\ June 1983 \\ Center for Research on Information Systems \\ Computer Applications and Information Systems Area \\ Graduate School of Business Administration \\ New York University
}

\author{
Working Paper Series \\ CRIS 非56 \\ GBA 非83-84(CR)
}

\begin{abstract}
Published in ERGONOMICS, 1984 Vol.27, No.6, pp.663-690
The order of the authors' names has been selected by chance to signify equal contribution to this paper. Addresses are: Computer Applications and Information Systems Area, NYU Graduate School of Business Administration, 90 Trinity Place, New York, NY 10006, (212)285-6086; Department of Industrial Engineering and Operations Research, Columbia University, New York, NY 10027, (212) 280-2935.

The authors are indebted to Dr. Judith Reitman-01son, Professor Ben Shneiderman, Dr. Phyllis Reisner, Professor Henry C. Lucas, Jr., and Professor Walter Reitman for their comments on a previous version of this paper.
\end{abstract}




\section{Abstract}

Evidence is reviewed that the operating characteristics of computer application systems, in addition to physical characteristics of display units (CRTs), are the cause of many observed effects on operator health and task effectiveness. These effects are hypothesized to occur through changes in task structure, and the man-machine redivision of labor that results when computer application systems are introduced into work settings. First, the association between task dimensions and models of operator performance effectiveness and well-being are reviewed. Second, application system design parameters that affect task structure are identified. Then, empirical evidence supporting this three part causal linkage application system parameters to task characteristics to operator effectiveness and health - is presented.

The findings suggest that by improving dialogue quality, taking advantage of two way communication to reduce uncertainty, using smaller and less integrated systems and matching system performance to operator needs a job can be created that is likely to improve both operator well-being and effectiveness.

Keywords

Information Systems, Systems Design, Software Design, Job Design, Task Environment. 


\subsection{Introduction}

Use of cathode ray tube displays (CRT's) in U.S. workplaces has increased at such a rapid pace that there has been little time for assessment of the effects of this new man-machine interface on human performance and health. Primary emphasis of research to date appears to have concentrated on the physical characteristics of CRT terminals themselves (Grandjean, 1980), including such parameters as screen luminosity and color, flicker rates, and character resolution, as well as ergonomic considerations, for example, seating position and keyboard location. Evidence of the effects of such factors on specific illnesses continues to be equivocal (for example, cataracts Zaret, 1980; AAO, 1982).

However, there is very consistent evidence of more generalized psychosomatic stress problems based on self-report data in a variety of studies from several countries (Smith et al., 1981; Johansson and Aronsson, 1980; Turner, 1980; Bradley, 1977). The implication of this consistent psychosomatic evidence is that the problem may not be solely the physical parameters of the CRT's themselves or the positioning of the display in the work setting, but additionally, the stress resulting from operating characteristics of the overall computer application system. By operating characteristics we mean the command sequences performed by the operator in order to control the system and the responses produced by the system. 
In support of this position, no one has suggested that complaints about using computer systems would be substantially diminished if printing terminals were substituted for CRT's, which would change many of the display's physical parameters. Thus, it is important to distinguish 'physical' problems based on CRT hardware and placement from problems that may arise due to the reallocation of tasks between man and machine and the content of the resulting human tasks.

In interpreting their findings Smith et al., 1981 observe, " .. there was not a strong relationship between the amount of time spent working at the VDT [CRT] and resultant health complaints ... Therefore, it seems likely that there must be other factors beyond the physical presence of the VDT [CRT] that contribute to the health complaints and stress level of the clerical operators" (p. 6-7). It is maintained that changes in task environment resulting from the redesign of work to make use of computer systems is likely to be one such factor.

As Johansson and Aronsson (1980) observe, "to the extent that differences between computer electronics and the human nervous system - with their respective reaction times - do underlie reports of tension, fatigue and so on, it is hardly surprising that special VDU [CRT] spectacles and better furniture design have not eliminated these strains." Supporting evidence comes from the fact that computer users with different task structures (i.e., same job with different divisions of labor between worker and computer) have different health outcomes (Bradley, 1981; Turner, 1980; Bjorn-Andersen, 1976), a conclusion supported in recent NIOSH studies (Smith et al., 1981). 
Designing effective man-machine systems involving high order human mental functions is harder than designing systems with a good physical fit (i.e., keyboard position or seating height). The cognitive processes involved in complex control situations are poorly understood whereas the physiological limitations of humans are quite well documented. In addition, the relevant characteristics of computer application systems are harder to measure than are the characteristics of a piece of hardware, and the research findings about these systems are not well organized for use by designers.

The goal of this paper is to structure relevant research findings into models which are meaningful to computer application designers. It is hypothesized (Diagram 1) that task characteristics intervene between computer application system design parameters and worker outcomes (Turner, 1980). When an application system is implemented, intentionally or not, labor is reallocated between man and machine resulting in a new set of tasks for both worker and machine -- i.e., the man-machine division of labor is changed. These tasks are then reintegrated into a functional system by giving the operator appropriate control sequences and system status information to complete the work.

\section{[PLACE DIAGRAM 1 ABOUT HERE]}

Substantiating this position requires forging a linkage between, 1) task characteristics that might effect the well being and performance effectiveness of workers using computer systems (section 2 of the paper and path I in Diagram 1), and 2) computer application 
system design parameters, such as those used in data-base management, process control, and word processing, which may effect task characteristics (section 3 of the paper and path II in Diagram 1). In section 4 of this paper the empirical evidence linking these sets of parameters is summarized in tables for use by system designers to relate technical system parameters to their effects on human behavior.

\subsection{Task Characteristics and Worker Outcomes}

In the sections below several literatures are reviewed for appropriate models in the areas of human signal detection, learning effectiveness, information processing, and coordination of tasks. The implications of this broad material is summarized in Diagram 2 .

\section{[PLACE DIAGRAM 2 ABOUT HERE]}

\subsection{Performance Effectiveness}

Welford (1976) has summarized the literature on performance effectiveness of work tasks in terms of an information processing model (see also Broadbent, 1971). The model states that an individual distinguishes relevant signals from the environment and, then, transfers associations between such signals and appropriate responses to long term memory for future use. Two primary themes affecting these mechanisms are, first, the importance of arousal level, and, second, the role of operator participation in learning and memory retention. 
2.1.1 Signal Detection Efficiency. A variety of factors affect how quickly and effectively an operator can work. 'Unpredictability' of information supplied to an operator by a system can decrease efficiency for several reasons. Operators will normally 'group' or 'code' information by time, location, color etc. If an entire group of signals can be 'batched' together by a human being's sensory apparatus, they can be processed by a single response sequence, increasing the individual's processing efficiency (Welford, 1976). Thus, 'patterning' or recognition of information sequences can improve processing efficiency (although not if patterning increases to the level of 'monotony', Zubek, 1964). Another reason that unpredictability diminishes efficiency, is that constant searching and concentration is required to detect infrequent signals, since it is impossible to forecast when an event will occur (i.e., enemy aircraft on radar screens, Broadbent, 1958, 1971). This constant energy expenditure quickly leads to fatigue and psychological stress (see section 2.2). Indeed, Johansson and Aronsson (1980) find unpredictable computer system breakdowns as the clearest contribution to job stress for clerical workers using computer application systems.

2.1.2 Task Arousal and Performance. Arousal level refers to a non-specific general activation level of the full nervous system (asleep-awake-alert) relating to a person's readiness to respond to environmental stimuli. Arousal level at work is primarily a function of task demands (i.e., processing load per unit time), but also can be effected by generalized stimulation from the environment, (for example, noise) and by the individual's emotional state. There is almost universal agreement (see discussion in Frankenhaeuser and 
Johansson, 1974) that performance effectiveness is related to arousal by a 'U-shaped' curve: ineffective response occurs when arousal is too low - because of errors of omission (Welford, 1976), or because of the fatiguing demands of self-motivated concentration. And ineffective response occurs when arousal is too high - because of errors of commission and fatigue. The nature of successfully achievable tasks vary with arousal (and visa-versa): a difficult task can be achieved only at a low overall arousal level (as well as within a very restricted arousal range); a simpler task may be facilitated by high arousal, and have success less dependent on arousal level.

\subsubsection{Operator Autonomy and Learning Effectiveness}

A broad theme in the performance effectiveness literature is the significance of operator autonomy in performance of skilled tasks. of course, an operator's own current skill level is a major determinant of tasks which he should be able to perform, but a dynamic view of complex task performance emphasizes the importance of learning new skills.

Several researchers (e.g., Bainbridge, 1974) point out that the task situation itself contains several important determinants of learning facility. As Welford (1976), Baker and Young (1960), and Belbin and Downs (1964) observe, an opportunity for active response to the task stimulus - and even control of subtask sequencing (Duncan, 1974) - facilitates memory retention for complex tasks. The operator executes a solution strategy and the machine 'feeds back' a performance measure confirming the operator's mental 'model' of complex system operation. Welford (1976) observes that active 
feedback facilitates learning both by allowing finer response adjustments to be made and by illuminating the limit of an action's effectiveness. An important implication of the need for active response is that the system must be prepared to accept all possible operator responses [1].

In more complex work situations, involving multiple tasks, again, a major parameter of effectiveness is found to be the operator's freedom in selecting a response strategy, for example, insuring safe landing patterns for aircraft (Sperandio, 1971) or supplying power to steelmaking furnaces (Bainbridge, 1972). Indeed, Bainbridge (1974) concludes that the goal of an operator must be formulated in broad terms (i.e., landing an aircraft safely in air traffic control) so as not to inadvertently restrict his solution strategy by predetermining intermediate goals (i.e., aircraft being held to minimum time to airport).

According to Umbers (1979), the primary determinant of operator effectiveness is the broad solution strategy adopted: whether it is 'closed loop' (feedback: action $\rightarrow$ error report $\rightarrow$ correction opposing error) or 'open loop' (feedforward: assessment of situation $\rightarrow$ prediction of future error $\rightarrow->$ preventive correction). In the most effective control processors, the operator has sufficient knowledge of system functioning, and sufficient information on environmental impacts to be able to predict the future state of the system and, thus, use open-loop strategies. He is able to take advance action against problems instead of having to wait for feedback in order to act. Closed-loop feedback may be used for final 'touch-up' corrections when open-loop strategies are used. 
Several factors may inhibit using open-loop strategies, however. Umbers (1979) observes that as the work load increases operators tend to switch from open-loop to closed-loop strategies (which usually result in less effective performance). Bainbridge (1974) explains that operators attempt to retain equilibrium in arousal level: when the situation has heavy demands (high arousal level), a planning strategy is selected implying little additional cortical arousal (a closed loop system).

Open loop strategies also require substantial experience; i.e., learning about system functioning is necessary before predictions of future states can be made. Work place design can inhibit these strategies by inadvertently placing important limitations on 'degrees of freedom' of action available to an operator (Sperandio, 1971): for example, biophysiologically restrictive environments (inappropriate light, heat, temperature); administrative procedures; and machine interfaces that limit skill usage (Kahn, 1981, discusses this problem as qualitative 'underload'). As an operator tries to vary his strategy in response to different work loads and the technology or administration resists, the technical [computer] aid which was useful at a certain task load level may become a stress factor at another level (Sperandio, 1971).

\subsection{Working Life Quality}

Both the learning effectiveness and the process control literatures concentrate primarily on the parameters of successful performance; much less attention has been devoted to understanding the mechanisms of performance breakdown - or operator distress. An 
umbrella term for degradation of performance in the information processing approach is 'fatigue'.

Although comprehensive models of why fatigue develops are sparse (Welford, 1976) [2], there is a well developed list of fatigue consequences formulated by Welford in terms of the information processing model. Heavy task loads lead to decreasing accuracy of signal discrimination, slowing of sensory responses, and irregular timing of responses. Of significance for complex tasks, fatigue also leads to disorganization of the operator's strategies for combining sub-tasks (Bartlett, 1943, Welford et al., 1950), including omission of infrequent tasks and disruption of short-term memory, possibly due to over use or loss of 'keeping track' information. These later two mechanisms imply that the actual work done by an operator will increase under fatigue since time saving encoding processes break down, further accelerating fatigue. Nevertheless, the above fatigue paradigm implies that even if overload induces fatigue, performance effectiveness will resume after a short recovery period.

2.2.1 Stress Consequences. Stress research goes beyond the issue of simple performance degradation to focus on global disruption of an operator's ability to function and his physical and mental health. Frustration of goals and delay of action are common themes.

In the stress model, performance disruption may extend far beyond the original task boundary and, through generalized 'tension' or 'anxiety', effect the individual's entire psychological orientation. The result may be loss of self esteem, social aggression, or sleep disruption (Langner and Michaels, 1961; Lazarus, 1966; Karasek, 
1979; Dohrenwend and Dohrenwend, 1974). Physical illness may also result, such as muscular aches (Karasek et al. 1982b); gastrointestinal problems (House et al.,1979); and cardiovascular disease (Karasek et al., 1981; Friedman et al. 1958; House et al., 1979; Kasl, 1980).

Such broad ranging consequences require an 'active' force for system disruption, not just the 'passive' fatigue of the information processing model. Under what circumstances does an individual's aroused energy switch from constructive performance to internally destructive strain? McGrath's (1976) simple 'overload' model of stress (overload occurs when environmental demands exceed an individual's ability to cope) suggests that the circumstances may be said to depend on the individual: his skill, experience and 'personality' (Welford, 1976). In Karasek's (1976, 1979) 'residual strain' model, task parameters also define a stressful circumstance: not only the magnitude of the load, but the individual's degree of freedom of action in the face of a demanding task [3], and the availability of social support and assistance.

Limitations on the operator's response strategy could be a direct result of the man-machine division of labor where the controlling factor is a computer application system's operating parameters. This may lead to a lack of task variety and rigid task prescriptions which have been associated with psychological stress and job dissatisfaction (Hackman and Lawler, 1971; Caplan et al., 1975; Garde11, 1971; Karasek, 1979). A rigid, machine paced task does not allow adjustment to daily variations in human capability, leading sometimes to excess strain and at other times to underutilized capacity, although 
empirical evidence on the effects of machine-paced tasks remains somewhat equivocal [4].

According to Karasek's model (1976, 1979), when an individual receives an appropriate signal (stressor) from the environment he prepares psychological and physiological mechanisms for a resolving 'action' placing the organism in a state of 'potential energy' (stress). However, if appropriate action cannot be taken after this arousal - because the appropriate actions are restricted by low job autonomy or are not known (insufficient knowledge) - the aroused energy must be dissipated (Ziegarnik, 1927; Henry and Cassel, 1969) and in the process may lead to deleterious physiological and psychological consequences (e.g., strain, illness). The stress model's focus on physically traumatic consequences of high levels of arousal and constant need for complex adaptation has been well documented using animal subjects by Selye (1973) and colleagues in several decades of research.

The effect of work load on strain and fatigue may, however, not always be linear - at very low task load levels added tasks may diminish boredom and strain (Siegal and Wolf, 1969). Frankenhaeuser and Johansson (1981) find that adrenaline, a measure of psychological strain, is elevated at both very low and very high work loads [5].

\subsubsection{Operator Independence. Another aspect of the man-machine} division of labor created (unintentional or not) by computer application systems are socially interdependent task structures. New dependencies form between application system operators and system support staffs, data entry groups, and computer operators as well as 
with supervisors and co-workers. Turner (1980) suggests that an operator's natural recourse in times of system breakdown or malfunction is to seek interpersonal assistance: if it is not obtainable, stress results. However, related findings from literature on 'social support' conclude that freely-chosen assistance and emotional support from co-workers and supervisors can diminish the adverse effects of stress on the individual (Larocco et al. 1980; Karasek et al. 1982a). These latter research findings implicate close emotional integration between individuals as an ameliorating ('stress buffering') mechanism. However, such positive interpersonal relations can be negatively affected by changes in work process that accompany 'labor restructuring' technologies (Trist and Bamforth, 1951). These associations highlight the importance of the often overlooked interpersonal aspects of task structure change.

\subsection{Summary of Task Characteristics That Influence Operator Well-Being and Performance}

The search for models of human behavior in performing sensory and control functions at a complex man-machine interface can be summarized with the following themes (refer to Diagram 2 and Table 1):

\section{[PLACE TABLE 1 ABOUT HERE]}

2.3.1 Dynamic Variation in Human Arousal Level and Work Load which Affects Both Effectiveness and Psychological Strain. The nervous system arousal level which is required to enable an operator to 
accomplish specific tasks varies in a complex non-linear manner according to the overall work load the operator faces and other sources of stress. Neither too little arousal, nor too much (corresponding, for example, to very heavy task loads) are optimal for effective performance. Extremes of arousal can also lead to adverse physiological changes - with severe illness possible under conditions of prolonged overload. This suggests that the operator's work load should be adjusted according to burdens imposed by related tasks and other operator stress sources, in order to keep arousal level within an acceptable range [6]. Achieving an arousal balance is also an important condition for learning effectiveness.

2.3.2 Operator Autonomy in Selection of a Control Strategy. It is found that operators neither learn individual tasks effectively, nor are able to build a clear model of overall system functioning without autonomy to alter control strategies. Without a clear conceptual model of a system an operator is unable to employ feed forward predictive strategies associated with effective performance. In the stress literature, lack of control when facing heavy task demands is associated with both psychological strain and physical illness: the operator is unable to most effectively allocate his personal resources, and may also face residual strain from tasks which require arousal, but frustrate required action.

2.3.3 Uncertainty in Machine Function at the Man-Machine Interface. Uncertainty in expectations of sensory loads and unanticipated system responses prevent an operator from effectively formulating input information and from being able to take optimum corrective action. 
Unexpected system breakdowns with unpredictable durations have been shown to be one of the greatest sources of operator psychological stress.

\subsubsection{Unanticipated Task Interdependencies and Exception Conditions} Resulting from Computer Application Systems. The interdependence of individuals and work groups are usually altered by the redivision of labor implicit in a new system design: an operator may become dependent on new work methods and consequently lose sources of assistance in task performance that were previously enjoyed. Another rarely examined consequence of computer application systems is that they may establish rigid procedures for accomplishing a task whose irregularities previously had been dealt with by a wide variety of non-computerized personal problem solving strategies. Irregularities not anticipated by system designers are converted into exception conditions - which can dramatically increase operator work load.

3.0 Application System Design Parameters and Task Characteristics

The first part of this paper identified themes relating task requirements to operator performance and well-being. Four aspects of the task environment are particularly important: operator autonomy over control strategy selection, operator uncertainty about system operation, altered task interdependencies, and overall work load relative to arousal level. In this section corresponding computer application system parameters are considered. 
Too often writers refer to loosely defined notions, such as 'user perceived system quality' or 'user friendly' without explaining the constituents of these notions or the mechanisms by which they influence human behavior. While few would disagree that 'ease-of-use' or 'fault tolerant' are desirable system features, they are concepts which are too general to provide much guidance to application designers. No one purposely makes a system 'hard' to use, but it is not clear, frequently, just what aspects of a system make it easy to use in a particular work setting or what trade-offs with other features are involved in acheiving this objective.

At the other extreme of detail, numerous prescriptions for designing specific system components exist, for example, screen layouts or dialogues (Martin, 1973). While these check lists may contain some useful information for inexperienced designers, as Shneiderman (1980a) observes, they often contain conflicting recommendations. Focusing on a part of a system, without a set of general principles, can encourage overlooking broader issues, such as job design, that may have far reaching consequences.

Researchers concerned with the 'human factors' of computer systems, have tended to be quite explicit in their meaning of ease-of-use, defining it in terms that permit quantitative measurement (for example, learning basic programming language functions and combining them into more complex queries) and performing experiments involving people using systems to do different kinds of tasks (Reisner, 1981). However, this research is mostly concerned with differences in programming language features (for example, syntactic form or degree of procedurality) or programming techniques (Sheil, 
1981) and is of more benefit in the design of programming languages or in programming than in application system design.

An objective of this paper is to identify those general application system parameters that influence the task dimensions identified above and are also meaningful to system designers; that is, reference factors designers consider during the design process. By linking system parameters to operator performance and well-being, through task dimensions, the consequences of specific design trade-offs should be more evident.

As Rouse (1981) observes, task-allocation decisions on the part of a system designer are tantamount to defining the human's job. These decisions should not be made in a piecemeal fashion, but rather on the basis of established principles. The design problem can be stated: given a particular set of tasks to be performed, which tasks will be performed manually, which tasks will be performed automatically, and which will be performed using some form of human-computer interaction. The central issue is the basis upon which these allocation decision will be made.

\subsection{Strategies for Task Allocation}

One approach to allocating tasks between humans and computers is to partition a set of tasks into (what is hoped will be) coherent subsets (Rouse, 1981). One subset is allocated to a human and the other to a computer on the basis of the match between the information processing demands (kinds of processing, amount of processing) of the task and the characteristics of the processor (Reitman, 1982). For 
example, it is generally acknowledged that humans are good at cognitive tasks, such as formulating generalizations, unstructured problem solving, and evaluation while computers are efficient at calculation, such as data transformation, model simulation and display tasks.

A related approach is to use an operator as a supervisory controller (Greenstein et al., 1981). The human becomes responsible for 1) monitoring, involving the detecting of events that require human action and the execution of appropriate action, 2) intervening, or resorting to manual control in response to unanticipated events or during maintenance, 3) planning/managing of the system itself, including reprogramming, and 4) operator training. The machine then performs all other functions.

An alternative strategy is to allocate all tasks that can be performed by a computer to a computer. Depending on the overall job, the human may experience wide fluctuations in load with periods of low activity. A variation of this theme is to allocate human tasks on the basis of efficient computer processing. The human performs those tasks that result in maximizing machine performance based on some objective system parameter.

Several considerations influence the choice of a task allocation strategy. The time interval over which a task is performed frequently defines acceptable processing modes. As Rouse (1981) notes, it is quite possible for a human to perform a job acceptably for a few minutes or hours while it would not be possible for him to endure the same task for a period of weeks, months, or a whole career. This is 
particularly true for mental work load (Moray, 1979), where levels of stress that are tolerable over a short period cannot be endured over a longer period and may lead to increased human error or disease (Karasek et al., 1982b).

A second major factor to be considered in the choice of a task allocation strategy is the question of who controls a system -- the human or a computer. There are any number of alternatives ranging from complete human control to the reverse. As Rouse (1981) points out unless control is explicit it is possible for the human to become confused about who is supposed to perform a particular task leading to decreased task performance effectiveness.

The basic philosophical and economic justification for new technologies, such as computers, is that they are 'tools' to extend human beings creative and productive capabilities. Such a perspective requires the operator to be 'incharge'. In reality, computer application systems are often designed first and operators are then expected to adapt to them.

Another issue influencing the choice of a task allocation strategy is the extent to which human operators will accept computer-aided decision making. A fourth factor is the degree of interaction among concurrent tasks, the problem being that task performance effectiveness may decrease when the same processing resource is required to process multiple, concurrent tasks (due to overhead and program complexity in a computer and limited short term memory in humans). 
The above allocation approaches all share one aspect in common -they are static and do not take into account changes in processor load as a function of time. They also fail to recognize that some tasks could be performed acceptably by either humans or computers (Rouse, 1981). These deficiencies suggest the notion of dynamic task allocation.

Chu and Rouse (1979) conclude that dynamic task allocation has numerous advantages including better use of system resources, less variability in the human's work load, and improved opportunity for learning. The basic idea behind dynamic task allocation is that tasks are assigned to the processor (human or machine) with the greatest instantaneous capacity for performing the task. This approach has the advantage of permitting adapting to performance level differences among operators as well as to one operator over time. For example, a system able to sense an operator's arousal level could dynamically reallocate tasks so as not to overload the human operator, while still maintaining overall system performance (see section 5.1 .3 ) or an operator could select a task allocation plan at the beginning of each work session.

In Diagram 3 those aspects of computer application systems that influence the task environment of operators in a man-machine system (are identified). The information processing model of operator performance effectiveness (Welford, 1976) suggests that humans form conceptual models of the process under control permitting the selection of different control strategies (Bainbridge, 1974). These models are used by an operator to interpret information about system operation in order to select a proper control sequence (Bainbridge, 
1974; Umber, 1979; Miller, 1981). It follows, then, that the dialogue between human and machine is key to the construction of these models. Indeed, as Greenstein et al., (1981) observe, the primary method of resolving coordination conflicts between an operator and a computer is to maximize the information supplied to each processor about present and planned actions of the other. Man-machine dialogue becomes the basis for all overt information transfer between operator and system and it provides the cues needed by an operator to invoke appropriate models of system operation.

\section{[PLACE DIAGRAM 3 ABOUT HERE]}

\subsection{Dialogue Quality}

At a general level, dialogue must not be in conflict with an operator's conceptual model of the process being controlled (Gaines and Facey, 1975) or his task based expectations. More specifically, the dialogue must provide 1) sufficient information about the current system state, 2) information about likely future states (transitions), and 3 ) information in a framework that is meaningful to the operator.

Information about current and future states is necessary for an operator to be able to apply either feedforward or feedback control techniques corresponding to open or closed loop control strategies. A meaningful framework implies that entities referred to in dialogue and the concepts related to those entities should be ones with which the operator is familiar and comfortable. That is, the entities and concepts should match the operator's task vocabulary. Furthermore, the system must be able to detect dialogue ambiguity and resolve it 
either logically or by clarification from the operator.

From the designers perspective several factors, representing trade-offs that effect an operator's task environment, influence dialogue structure.

3.2.1 Efficiency is a measure of the amount of communication (number of tokens) required to express a command or message. This effects an operator's work load in generating commands and in interpreting messages. For many classes of commands, formal languages are likely to be more efficient than natural languages (that is, native tongue). However, the extent to which a formal language can be used depends on an operator's level of specialized knowledge.

3.2.2 Naturalness is the degree to which the dialogue form is similar to an operator's native tongue. Formal languages constrains an operator to a rigid format (syntax) in order to gain benefits of precision and efficiency. Departure from this format causes an error, but since formal, (computer) language syntax follows prescribed rules, these errors can be detected by computer processing. Formal language requires learning which may be a barrier for inexperienced or infrequent operators. However, as Shneiderman (1980b) notes, current natural (computer) languages have grammar and domain restrictions that result in confusion with regular language (pro-active interference). The trade-off between message naturalness and efficiency could be resolved by dynamic adjustment.

3.2.3 Style is the covert context of messages or commands. It can 
range from cryptic 'IAD367E2 - DS OVERFLOW' to friendly 'THIS SAVE CANNOT BE MADE BECAUSE YOUR DIRECTORY IS FULL. PLEASE SELECT OPTION FROM THE FOLLOWING ERROR LIST'. Shneiderman (1980b) observes that knowledgeable users are put off by anthropomorphized systems with advice directed to beginners, probably because the dialogue style is inconsistent with the expert operator's model of the system. This suggests using impersonal, formal dialogues for experienced operators.

\subsubsection{Directivity is the extent to which a system permits two way} communication between operator and computer. Systems that permit two way communication (for example, certain classes of interactive systems) have the potential for resolving ambiguity in messages or commands. A richer dialogue leading to more complete resolution of operator uncertainty, and consequently improved performance and well being, is possible when system designers permit operator initiated clarification dialogues.

Which of these dialogue factors predominate depends largely on the target operator population and the task characteristics (Shneiderman, 1980b). For instance, inexperienced, infrequent users are affected by naturalness and message style while experienced, frequent users are likely to be concerned with dialogue efficiency [7]. Application domains that involve extensive system interaction could have efficiency and directivity as important parameters (because operators will be prepared to learn a formal language in order to reduce the amount of effort they must expend in generating commands), while domains with little interaction may have naturalness and directivity as important criteria. Individual differences among 
operators (for example, experience, education, personality type or decision style) as well as differences in task difficulty may also account for variations in the importance of various dialogue quality parameters.

\section{3 Work Flow}

Another important factor that influences the allocation of tasks between operator and machine is the work flow or organization of the processing system. At one extreme, systems may be organized on a work 'process' basis (i.e., as a 'continuous' process) where all of the processing of a particular type is performed before the next processing step is initiated. Process based systems are relatively easy to design because there is little interaction between sub-tasks and efficient, because processing overhead can be kept to a minimum. However, there is a tendency for these design principles (for example, task specialization) to impinge upon an operator's task structure resulting in small pieces of disconnected and repetitive work under machine control.

At the other extreme, systems may be organized on a 'work unit' basis (i.e., as a 'discrete' process) where all processing takes place on a particular item or transaction before the next item is handled. Work unit based systems are relatively difficult to design because of communication, control, and coordination requirements between concurrent sub-tasks and conflicts over shared resources. However, these discrete work modules lend themselves to decentralized processing structures in which human intervention can be more easily accomodated. In computer application systems, process based systems 
tend to be implemented by 'batch' processing organizations, work unit based systems are usually designed as 'on-line' or interactive systems.

From the standpoint of the system designer, work flow is a fundamental decision from which most other design issues follow. Hardware configurations and operating systems are different for on-line systems than they are for batch systems. For example, a communications controller is needed for on-line systems and the operating system has to provide terminal support as well as a method for allocating resources among active users. The control structure for invoking application system modules is different for on-line systems than for batch systems and the module structures are different.

Work flow also defines the basic structure of an application system which, in turn, determines fundamental aspects of the new division of labor: the sequence and content of tasks performed by an operator. In batch systems operators tend to be viewed as machines; they perform repetitive, short processing cycle activities such as data input, text entry, or data correction. The continuous nature of the processing flow encourages job specialization since interaction with the system is severely limited (e.g., internal files not being continuously available or only one way communication permitted). The system is perceived as remote from an operator and little attempt is made to provide a coherent model of its operation; it is, in short, an inflexible and distant task master. For instance, detection of input data errors takes longer since they are not recognized until after the data are processed, frequently in an over night edit run. 
Sometimes errors are corrected by a person other than the one who submitted the original input increasing operator overhead. The result of a division of labor based on the continuous process model is a job with markedly different content than one based on the discrete process model -- a job with different work load, control over work processes, and interdependence with other workers.

\subsection{System Complexity}

System complexity directly effects the man-machine division of labor though the number of additional entities (e.g., other users, system operating procedures) an operator must work with in accomplishing his task. Given that an operator needs to effectively use a 'mental model' in order to resolve problems arising in system usage, then the complexity of the system will be a factor in the ease with which this model may be developed and utilized. With simple systems, it is relatively easy to determine the system state since there are few possible conditions. Complex systems have many states and it is difficult to tell the internal state of the system from the content of operator messages. System complexity may be thought of as having three components.

3.4.1 Functional Complexity refers to the number and importance of functional activities included in an application system. Software systems with a rich set of functional activities provide more complete operator support, but at the expense of system size, performance, and cost, since each new function requires a processing routine. Furthermore, systems may require subroutines from other applications, 
data files from another system, or hardware manipulations beyond the domain of the immediate system the operator understands (such as tape or disk pack mounts).

3.4.2 Internal Complexity is a measure of application system size and the intricacy of the technology used to build a system. Large systems place demands on operators to understand and hence to learn, to determine status, and to control. As systems grow, for instance, in message activity or data base size, internal timing becomes more critical and the operation of the system is more difficult to predict and to understand.

3.4.3 External Complexity is a description of a system's community of users. Systems that serve many heterogeneous user groups at different geographic locations make agreeing on system requirements difficult (Turner, 1981a). No one user is able to influence a system without negotiations with the others, for example, in changing the format of output reports. This interdependence among operators is a major determinant of the man-machine division of labor with the result that the task environment of any one operator is often sub-optimal.

System designers frequently strive for complexity because it permits them to work with the latest equipment or because it is promoted by their 'technical' ethos rather than it being a rational solution for increasing man-machine system performance or operator well-being. Sometimes complexity is encouraged by an organizational setting, often at the expense of the people who will operate the system. 


\section{5 System Performance}

The fifth aspect of system design that particularly affects operators is the way a system performs. Systems that fail to meet performance requirements both decrease the effectiveness of a man-machine system as well as increase operator strain. Frustration occurs when the operator is in a state of readiness to accomplish a task (high arousal), but the system blocks effective action, for example, by long response time during text data entry. Performance is composed of two components: dynamic performance and resilience.

3.5.1 Dynamic performance refers to those performance metrics that are important measures of system 'throughput' for a particular application. For instance, on-line systems usually need response times of several seconds or shorter above which operator performance degrades. Overall response time may depend on data set locations on physical devices, operating or monitor system structure, hardware architecture and speed, and system loading. Each situation will have its own set of critical performance factors. Complicating matters, these factors will have variable rather than constant values, so it is the distribution of these performance factor values over time and their interaction that determines performance.

An important performance factor often overlooked is the 'frequency' with which an application system fails and the 'duration' of its unavailability. From the operator's perspective, this may be the most important of all performance measures since unavailability of a system frequently prevents useful work from being accomplished. Even though a system fails, work deadlines are seldom relaxed. The 
operator is then placed in the awkward position of wanting to work, but being prevented by the system from doing so. Sometime in the future, when the system becomes available, the operator will have to work doubly hard to meet the deadline. The frustration, uncertainty, and work stress in this situation can cause serious psychological and physiological damage (Johansson and Aronsson, 1980).

System designers have several ways to achieve robustness and thereby reduce the impact of system failure on operators. The reliability of hardware, the degree of parallelism in hardware design, and the quality of an operating system influence the frequency with which a system fails. The amount of system status information available to an operator when an error occurs, the likelihood of data loss or data base damage during the failure, and amount of knowledge and effort required for recovery, determines how much work will be required for recovery and how uncertain will be the process.

\subsubsection{Resilience refers to the way a system responds when an error} is encountered. Operator errors can be of form, such as misspellings, which lend themselves to program detection and correction. Or they can be errors of meaning, where the form of the command is correct, but it is used in an improper context. To be able to recognize and correct errors of form requires a system to have either a simple command set or fairly complicated error recovery routines because of the large number of possible error conditions. 
Handing errors of meaning requires some form of limited intelligence in a system. Systems can contain a representation of domain specific knowledge than can be used for deductive reasoning about the failure. (c.f., Davis, 1977, for a description of MYCIN, a knowledge based decision aiding system for infection diagnosis and therapy selection). Command sequences can be analyzed to deduce intent and deviations from prescribed patterns recognized. Systems with these capabilities are mostly experimental and the techniques on which they are based, such as methods of knowledge representation, are not in the usual repertoire of application designers.

\subsection{Summary of Application System Design Parameters That Influence Operator Task Environments.}

In summary, it has been argued that the strategy selected for allocating tasks between man and machine determines the content of an operator's job. These strategies can range from a matching of the information processing requirements of a task with the capabilities of a processor, to allocating all tasks that can be done by computer to a computer. Tasks may also be statically or dynamically allocated with evidence that dynamic allocation provides the highest overall system performance.

It is maintained that at least four other factors contribute to performance and the quality of an operator's job. Dialogue content and form provide the fundamental means of communication between man and machine. Work flow determines the way that a system is organized. Complexity influences the ease with which a system can be understood and changed. Finally, performance, and particularly the way a system 
responds to errors, influences an operator's ability to acquire skill in using the system.

Hypothesized associations between task characteristics and these computer system parameters are shown in Table 2 (and Diagram 3). These hypotheses may be represented at the grossest level in terms of two patterns: one involving the organization of work and the other related to system parameters. The task characteristics of workload, uncertainty and interdependence all decrease as work flow becomes more discrete (i.e., interactive) largely because an operator has more latitude in selecting work strategies and, thus, is better able to adapt to changing work demands.

\section{[PLACE TABLE 2 ABOUT HERE]}

The second general pattern is the improvement in task characteristics associated with improvements in system design parameters, that is, as dialogue quality and performance improve and system complexity decreases. With undifferentiated systems (that is, systems where parameters are not recorded), increasing amounts of usage lead to increased work load, uncertainty and interdependence. The actual evidence for these hypotheses is presented in the following section.

4.0 Research Support for Relationships Among Computer System Design Parameters, Operator Task Characteristics and Outcomes. 
One of the goals of this paper is to demonstrate confirming evidence for the complete causal chain from computer system parameters to effects on operator behavior (Diagram 1). Evidence for the direct causal pathway (path III) is scarce, although what evidence is available is discussed in section 4.2. More voluminous is the evidence for the indirect pathway composed of the two sub-models, paths I and II in Diagram 1. The association between operator task characteristics, performance, and well-being is summarized in Table 1 without detailed discussion since the literature is more widely known. The empirical evidence for associations between computer system design parameters and task characteristics is summarized in Table 2 and discussed below.

4.1 Empirical Evidence Linking Computer Application System Parameters with Task Characteristics.

4.1.1 Evidence for Work Load Effects. Almost all researchers have found a positive relationship between operator work load and intensity of computer use. Turner (1980), in a study of mortgage loan servicing workers concluded that work load increased with the amount of work done on a computer (table 3 ). In a study of four newspapers and one insurance company, Smith et al., (1981) found a significant difference in work pressure and in quantitative work load between clerks that used computer systems and a control group that did not (table 4 ). Kling (1978), studying office workers in 42 cities, reported increases in job pressure attributable to using computer systems.

[PLACE TABLE 3 AND TABLE 4 ABOUT HERE] 
Turner (1980) found a relationship between perceived operator work load and the type of application system used. Operators (performing the same job) using batch processing systems reported greater work load than operators using systems that were more interactive. This is consistent with the notion that batch systems are continuous process systems that result in machine paced operator jobs performed to tight deadines.

A relationship has been shown between operator work load and complexity of the system used (Turner, 1980). Complexity was associated with increased work load for on-line systems and decreased work loan for batch processing systems. Turner reasoned that complexity decreased system performance and made the operator's model of system operation more complicated in the on-line case resulting in relatively greater workload. For batch systems, complexity is related to greater functionality, thus reducing workload.

The affects of various system performance factors on work load is well documented in the literature, the general relationship being ' $U$ ' shaped: for example, too fast or too slow a response time is associated with increased work load (Barbar, 1979).

\subsubsection{Evidence for Operator Autonomy Effects. The evidence for the} effects of application system parameters on operator autonomy are equivocal. Smith et al., (1981) found that clerks using computers reported significantly less autonomy and greater supervisory control than control groups not using computer systems (table 4). Similar findings were reported by Bradley (1977) and Mann and Williams (1960), the explanation being that many application systems are rigidly 
programmed and do not permit deviation from a prescribed activity sequence. However, Turner (1980), Kling (1978), and Sheppard (1971) all found no evidence of differences in autonomy between workers using computer systems and those that did not. Turner (1980) observed, when controlling for job level, that autonomy was relatively independent of the degree of computer use and showed more variation among firms than within work groups.

4.1.3 Evidence for Interdependence Effects. Turner (1980) found a positive association between interdependence and perceived work load which he reasoned resulted from computer use (table 3). He speculated that this interdependence resulted from the need to resolve exception conditions that arise when working with computer application systems. Kling (1978) also found workers reported an increase in dealing with others as a result of using computers, as did Mann and Williams (1960). Bradley (1977), however, found less interdependence as a result of computer use. It is interesting to note that, computer determined interdependence appears to have different causes and consequences than individually prescribed interdependence. It requires an operator to interrupt his job to assist a fellow worker or to seek assistance himself. As Johansson and Aronsson (1980) observe, in working with computers, independence (rather than interdependence) is a source of job satisfaction, although social interaction among coworkers and supervisors, in other work contexts, has a strong positive correlation with job satisfaction (Karasek et al. 1982a). 
4.2 Empirical Evidence Linking Computer Application

System Parameters Directly with Operator Outcomes

As previously mentioned, the evidence for a direct causal path from application system parameters to operator effectiveness (Diagram 1, path III) is sparse, and what evidence exists is equivocal.

4.2.1 Evidence for Well-Being Effects. Inconsistent results have been found relating the amount of computer system use and indicators of operator well-being. Turner(1980) in studying the same clerical job found no significant direct association between the degree of computer use reported and measures of psychological strain or job satisfaction (table 3 ), although the indirect path through task content was confirmed. Neither did he find differences in mean values of reported psychological strain or job satisfaction between work groups (performing the same job) that were heavy or light users of computer systems. Similar findings have been reported by $\mathrm{Kling}$ (1978), Kraemer et al. (1981), and Smith et al. (1981). However, Mann and Williams (1960) observed that workers reported greater job satisfaction after the move of an accounting system to a computer, while Bradley (1977) has reported decreased job satisfaction in more intensely computerized jobs.

There is little research relating computer application system parameters, such as dialogue quality, complexity, performance or work flow to operator well being. Turner (1980) found no direct association between complexity or work-flow and well being . Bjorn-Andersen (1976) has reported that a move from manual to batch processing resulted in an increase in job satisfaction for clerks most 
directly using a system, while a move from batch to on-line processing produced a decrease in satisfaction. Shneiderman (1982) reports higher subjective evaluations of a text editor on the basis of improved dialogue quality.

Kennedy and Edmonds (1974) observed that variable (i.e., unpredictable) delays are sources of operator stress. Johansson and Aronsson (1980) found that interruptions in computer service [8] were associated with increased adrenaline, blood pressure, and heart rate on the part of operators waiting for system to become available. The operators also felt more irritated and rushed as well as less relaxed than under ordinary working conditions.

4.2.2 Evidence for Performance Effectivenss Effects. There are relatively few studies of the affects of computer use on productivity or performance although there is considerable circumstantial evidence that, for clerical work, computers can produce productivity gains over manual methods (McKinsey, 1963). Turner (1982, 1980) found a significant improvement in productivity between work groups (performing the same clerical job) that were high and low users of computer systems, even when controlling for organization size. This finding is consistent with the productivity literature which generally associates productivity gains with the application of technology (Katzell, et al., 1977). However, Kraemer et al. (1981) found productivity gains as a result of using computer systems in only one out of five functional areas of local government, and that one performed the most routine function. 
There is considerably more evidence relating computer application system parameters to operator performance. Shneiderman (1982) reports a reduction in work errors for subjects using a text editor with improved dialogue quality. Turner (1980) found a significant improvement in productivity between work groups (performing the same job) using batch and on-line systems. In a laboratory experiment, Turner et al. (1982), found no difference in performance between subjects using a restricted natural language to query an application data base and those using a formal, more structured language. In field experiments the structured language performed better than the natural language.

In summary, although there is some evidence supporting the direct path between operator well-being or performance and computer application system parameters, the overall impression, based on the propronderence of results, is that these effects are moderated by the operator's task characteristics. That is, the decision to use a computer application system in a job results in a new man-machines division of labor that produces a different mix of tasks for the human to perform, which then effects the human's well-being and the system's overall performance. 
5.0 Improving Computer Application Systems - Implications for Research and Practice

This paper has argued that the consistent self-reports of psychosomatic stress in jobs using CRTs may be due to the operating characteristics of the overall system rather than just the physical parameters of the CRTs themselves. A model that relates operator well-being and performance effetiveness to task environment characteristics which are influenced by computer application system parameters has been presented along with empirical evidence supporting the model.

While much more work must be done in investigating the relationship between task environment changes and application system parameters, the studies performed to date do present a rather compelling picture. For clerical jobs, where workers have little choice but to use a computer application system after a job has been redesigned to incorporate one, the quality of the job appears to be poorer. In general work load and interdependence tend to increase with evidence of greater mental strain (this pattern is particularly evident in table 3 and to a certain extent, in table 4). Not only are these outcomes related to the amount of work done using a computer system, but also to the system's characteristics.

Bjorn-Anderson and Hedberg (1977) observe that system designers do not purposely make jobs poorer, they simply overlook job design issues. Designers couple a lack of knowledge about work load and task interdependencies imposed by a system with untested assumptions about an operator's potential to acquire skills and to make task related 
decisions. Designers' decisions are frequently guided by never stated (indeed, often unconscious) assumptions that operators are unmotivated and unintelligent, can not and do not want to understand basic aspects of overall system operation, exist only as a coordinated pair of eyes and hands (Davis and Taylor, 1974), or that management can be satisfied with more performance from a system (e.g., more transactions processed per hour) regardless of the broader consequences to the firm, including those to its human resources.

The research findings also suggest that computer application systems need not have an adverse effect on working life quality - nor effectiveness penalties which offset technological advantages. The implication of the computer system-task dimension associations shown in table 3 is that by improving dialogue quality, taking advantage of two way communication to reduce uncertainty, simplifying application design with smaller and less integrated systems, and matching system performance to operator needs, a job can be created that may result in improving operator well-being and effectiveness.

\subsection{Design Recommendations}

While a full discussion of application system design alternatives is beyond the scope of this paper, several recommendations emerge from these studies which do appear to have broad applicability.

5.1.1 Dialogue Quality. Improving dialogue quality can increase an operator's ability to group information received more effectively. Varying dialogue naturalness with an operator's skill level can contribute to learning effectiveness. Together with information on 
overall system status, high quality dialogue can enable an operator to construct a predictive model of system operation that both anticipates future problems and and can diminish the risk of psychological strain.

5.1.2 Operator Skill Acquisition. Systems should be designed with an understanding of the interplay between the skill repertoire needed to perform complicated tasks, system complexity, and operator learning. Inexperienced users may become experienced in a short period of time if a system supports self documentation, locally defined command sequences, abbreviations and synonyms, explanations of decisions or recommendations made by the system, and other skill acquisition features.

Many observers recommend giving operators more decision latitude as a way of increasing control over their work, permitting them greater self realization, assisting in acquiring new skills, and thus increasing job satisfaction (Mumford and Weir, 1980; Bjorn-Andersen and Hedberg, 1977; Turner, 1980). The data in table 3 supports the notion that increased latitude over work related decisions, such as the order in which tasks are performed, is positively related to job satisfaction, suggesting this approach as a useful strategy in job design. This recommendation is consistent with the job enrichment literature.

5.1.3 Adaptable Systems. Another important possibility is that systems be designed to be dynamically adaptable to individual operators; for instance, to skill level or state of arousal. Broadly, this may be accomplished by adjusting the allocation of tasks 
between system and operator, and by modifying dialogue characteristics. Most operational level application systems provide no features for static individual operator customization beyond the physical positioning of equipment, yet the techniques for accomplishing this are well known.

As Bainbridge (1974) suggests, operators may adapt their strategies for using and controlling a system to the overall work load in order to maintain a constant arousal level. If a system can not adapt to these changes in operator strategy, performance deterioration and stress result (this notion raises questions of possible confusion in task allocations between man and machine).

Rouse (1981) suggests an approach to system design where continuous operator monitoring, covert communication between operator and system (where the system deduces the operator's state from his task performance), or direct communication provide information for a system to adapt to changing operator capabilities. Thus, the overall system processing strategy might be changed for an operator who was in an exceptionally 'eager' or 'fatigued' state. In the former situation, a system might reconfigure to shift some of the processing normally done to the operator, modify message handling to accelerate system response and alter dialogue style parameters. In the later 'fatigued' situation, the system may assume more tasks, reduce the amount of information displayed and highlight important data, advise the operator of the implications of certain courses of action, and safeguard against potentially disastrous operator error. For example, Rouse (1981) suggests increasing the proportion of menu type responses, in this situation, in order to reduce the length of 
operator messages and the likelihood of form errors. Computer processing may then emphasize corrective adjustments instead of predicting future system states.

This approach suggests building dynamic systems that can adapt to the state of the operator rather than static, configurable or unchangeable systems. The overall division of labor between man and machine can be made dependent on limitations and variabilities of human information processing rather than being a rigid guideline for human performance and organization structure.

The current trend in the used of packaged application software (that is, a previously written application program that may be specially configured by the specification of parameters) to speed application development may complicate the application system designer's job. While the amount of coding is reduced, packaged software may be even more inflexible than custom designed systems, resulting in increasing the number of exception conditions, creating totally unexpected interdependencies, and multiplying restrictions on operator autonomy in strategy selection. Clearly packaged software should be originally designed to allow adjustment of the important man-machine integration parameters, or the overall impact of computer application systems in the future could become decidedly worse.

\subsection{Limitations}

While this analysis suggests many positive directions, it also has limitations. The design solutions are really multi-factorial and involve interdependent trade-offs, so it often makes so sense to speak 
of improving each system parameter independently. For instance, dialogue quality and performance may be compromised by the need to support a multiple user community. Also, table 3 displays simple, linear associations, but clearly thresholds and interactions between parameters occur which limit full generalization. For example, on-line processing could increase work load if carried to extremes, or systems could easily be designed to allow operators so much autonomy in strategy and work process selection that decision burdens develop.

The issue of system development cost has not been considered in this analysis. Design techniques which initially appear prohibitively expensive frequently become accepted and packaged in a manner that does not greatly increase total system development cost (e.g., generalized data base management systems).

Another limitation in this conceptualizion is that many aspects of the new man-machine division of labor may be determined by a general philosophy of task design (e.g., rationalization of tasks) without reference to a particular application system. There may also be broad objectives for organizational change, for example, isolation of specialized tasks or the gathering of task performance data that constrain a designer. What is crucial here is to make it clear to job designers, in general, that a computer application system, in itself, does not automatically mean restriction in an operator's freedom of action. Indeed, computer systems might well be used to enhance an operator's job and leverage human skills. 
6.0 Conclusion

The true job of the 'multi-disciplinary' computer application system designer is to address the full range of relevant issues discussed above. His job will be more complex than that of present designers - such is the cost to design truly effective and humane systems. Operator performance and well-being are a function of three factors: The job being performed, the computer application system, and the operator himself. It is the operator who presently bares all the adaptive burden. As Bjorn-Andersen and Hedberg (1977) suggest, the operator's potential must be the starting point, instead of the residual after thought, for system design. Only then can it be said that computer application systems have been designed as a tool to enhance human capabilities, and not the reverse. Demonstrating this to be the case is the next important step for researchers and practitioners to take. 
Center for Digital Economy Research Stern School of Business

Working Paper IS-83-84 


\section{NOTES}

[1] - It is important to distinguish choice of strategy to achieve a complex goal, which facilitates learning, from 'choice response' experiments in which a larger number of choices for the subject are equated with information processing load.

[2] - The physiological model of muscle fatigue does not seem applicable (Welford, 1976) and existing explanations relatable to task structure are often based on extremely general premises - such as McGrath's (1976) formulation: 'overload occurs when environmental demands exceed the individual's capacity to meet them'. The question is, what are the parameters of demands and capacities? Bainbridge's (1974) research suggests the problem: the actual demand on an operator will depend upon the solution strategy he selects. The solution strategy in turn is constrained not only by the operator's skills and arousal - at the present time - but of degrees of freedom of action available to the operator. Furthermore Bainbridge has observed that the operators' skill capacity - in the future - is itself a function of present task conditions.

[3] - For confirming evidence see, Broadbent, 1981; Benninghaus, 1981; Goitein and Seashore, 1980; Freeman and Jucker, 1980; Gardell, 1979; Aronsson, 1980; Karasek et al., 1981b. This mechanism closely parallels the findings by Bainbridge, 1974 and Sperandio, 1971 that restriction in operator flexibility will limit performance effectiveness.

[4] - Salvendy, 1981 maintains that, after controlling for all the other restrictive factors in machine paced jobs, machine pacing itself contributed little additional to stress. On the other hand, Frankenhaeuser and Gardell, 1979, and Ager et al., 1975, observe substantial health problems for machine-pacing for sawmill workers.

[5] - Since most work environments have significant loads, even at slack times, one would expect increasing strain with increasing work load.

[6] - It is likely that a job will have quite sufficient challenges to bring arousal to mid-range, in which case additional work load could lead to arousal overload, inducing both a decrease in performance effectiveness and an increase in psychological strain.

[7] - Many systens have 'help' commands and 'expert' modes that provide an operator with some assistance. Help functions require considerable knowledge in order to be used. They also usually imply a hierarchical structure which can be time consuming to traverse. An expert mode provides some customizing, although the selection of level 
is limited.

[8] - Although large commercial computer installations run between 5 to 2 percent down time, the frequency of interruption is much greater than these figures would indicate with several crashes per week not being uncommon. Even a software failure requires up to thirty minutes to restart application systems and to resume remote service. Certain operating system and hardware architectures are more resilent than others and uninterrupted service has become the objective of a family of systems (e.g., Tandem Computers). 


\section{BIBLIOGRAPHY}

1. Ager, B., Aminoff, S., Baneryd, K., Englund, A., Nerell, G., Nilsson, C., Saarman, E. and Sodergvist, A., 1975, 'Arbetsmiljon i sagverk. En tvarvetenskaplig undersokning.' Undersokningrapport AM 101/75. Stockholm (Arbetarskyddsstyrelsen).

2. American Academy of Ophthalmology, 1982, 'Information About Eye Care,' San Francisco, California.

3. Aronssen, G., 1980, 'Lokaltrafiken som arbetsmiljo delrapport 1; Arbetsforhallanden och halsa.' Preliminary Report, Psychological Institutionen, Stockholm University, Stockholm, July.

4. Bainbridge, L, 1972, 'An Analysis of a Verbal Protocol from a process control task,' unpublished $\mathrm{Ph}$. D. Thesis, University of Bristol.

5. Bainbridge, L., 1974, 'Problems in the Assessment of Mental Load,' Le Travil Humain, 37, 2, pp. 279-302.

6. Baker, C. and Young, F., 1960, 'Feedback During Training and Retention of Major Skills. Canadian Journal of Psychology, 1973, 25, pp. 229-240.

7. Barber, R., 1979, 'Response Time, Operator Productivity and Job Satisfaction,' Ph.D. dissertation, New York University, GBA Working Paper No. 79-53.

8. Bartlett, F., 1943, 'Fatigue Following Highly Skilled Work,' Proceedings of the Royal Society, 131, pp. 247-257.

9. Belbin, E. and Downs S., 1964, 'Activity Learning and the older Worker,' Ergonomics, 7, pp. 429-437.

10. Bjorn-Anderson, N., 1976, 'Organizational Aspects of System Design,' Data, 12, pp. 75-81.

11. Bjorn-Anderson, N. and Bo L.T. Hedberg, 1977, 'Designing Information Systems in an organizational Perspective,' TIMS Studies in the Management Sciences, 5, pp. 125-142.

12. Bradley, G., 1977, 'Computerization and Some Psychological Factors in the Work Environment' in Reducing Occupation Stress, U.S. Department of Health, Education and Welfare, Washington: NIOSH 
13. Broadbent, D.E., 1958, Perception and Communication, Pergamon Press, London.

14. Broadbent, D.E., 1971, Decision and Stress, Academic Press, London.

15. Broadbent, D.E., and Gath, D., 1981, 'Symptom Levels in Assembly Line Workers." Report to the British Mental Research Council; Mimeo; University of oxford, Department of Experimental Psychology, Oxford, England.

16. Caplan, R.D., S. Cobb, J.R.P., French, R. Van Harrison, and R. Pinneau, 1975, 'Job Demands and Worker Health,' National Institute for Occupational Safety and Health Publication, No. 75-160, Washington, DC.

17. Chu, Y. and Rouse, W., 1979, 'Adaptive Allocation of Decision Making Responsibility Between Human and Computer in Multitask Situations, ' IEEE Trans. Syst.: Man. Cybern. (SMC-9) 12 (Dec), pp. 769-778.

18. Davis, L.E., and Taylor, J.C., 1975, 'Technology Effects on Job Work and organizational Structure: A Contingency View,' in L.E. Davis and A.B. Cherns (eds.) The Quality of Working Life, Vol. I, The Free Press, New York.

19. Davis, R., 1977, 'A DSS for Diagnosis and Therapy,' Data Base, 8, 3 (Winter) pp. 58-72.

20. Dohrenwend, B. and Dohrenwend, B., 1974, Stressful Life Events, Their Nature and Effects, New York, Wiley.

21. Duncan, K., 1974, 'Analytical Techniques in Training Design,' in Edwards, E. and Lees, F; (Eds.). The Human Operator in Process Control, Taylor and Francis, London.

22. Frankenhaeser, M. and Gardell, B., 1976, ' Underload and Overload in Working Life: Outline of a Multidisciplinary Approach, ' Journal of Human Stress, 2 , pp. 35-46.

23. Frankenhaeser, M. and Johansson, B., 1974, 'On the Psychological Consequences of Understimulation and Overstimulation,' Reports from the Psychological Laboratories, University of Stockholm, Supplement 25, August.

24. Friedman, R., Rosenman, R.H., and Carroll, V., 1958, ' Changes in Serum Cholesterol and Blood Clotting Time in Men Subjected to Cyclic Variation of Occupational Stress,' Circulation, 17, pp. 852-861. 
25. Gaines, B. and P. Facey, 1975, 'Some Experience in Interactive System Development and Applications,' Proceedings of the IEEE, 63, 6 (June), pp. 894-911.

26. Gardell, B., 1971, Produktionsteknik och arbetsgladje, stockholm: Personal-administrativa Radet.

27. Gardel1, B., 1979, Tjanstemannes Arbetmiljoer:

Psycholosocial Arbetsmiljo Och Halso. Preliminar Rapport. Psychologiska Institutionen, Stockholm University, Report No. 24.

28. Goiten, B., Seashore, S., 1980, 'Worker Participation: A National Survey Report.' Survey Research Center, University of Michigan. Ann Arbor, Michigan.

29. Grandjean, E., 1980, 'Ergonomics of VDU's: Review of Present Knowledge." In Ergonomic Aspects of Visual Display Units, Proceedings of the International Workshop, Milan, Italy, March.

30. Greenstein, J., R. Williges, and B. Williges, 1981, 'Human-Computer Dialogue Design: Hardware and Software, " proceedings of the Fall Industrial Engineering Conference.

31. Hackman, J. Richard and Lawler, Edward E., 1971, 'Employee Reactions to Job Characteristics,' Journal of Applied Psychology Monograph, 55, pp. 259-286.

32. Henry, J., and Cassel, J., 1969, 'Psychological Factors in Essential Hypertension, Recent Epidemiological and Animal Experimental Evidence,' American Journal of Epidemiology, 90, pp. 171-200.

33. House, J., Wells, J., McMichael, A., Kaplan, B., and Landerman, L., 1979, 'Occupational Health and Stress Among Factory Workers," Journal of Health and Social Behavior, 20, pp. 39-160.

34. Insel, P. and R. Moos, 1974, 'Work Environment Scales - Form S,' Consulting Psychologist Press, Inc., Palo Alto, CA.

35. Johansson, G., and Aronsson, G., 1980, 'Stress Reactions in Computerized Administrative work,' Reports from the Department of Psychology, Stockholm University, Supplement 50, November.

36. Kahn, R.L., 1981, 'Work and Health, Some Psychosocial Effects of Advanced Technology,' in Gardell, B., and Johansson, G. (Eds.): Working Life, A Social Science Contribution to Work Reform, Wiley. London. 
37. Karasek, R.A., 1976, 'The Impact of the Work Environment on Life Outside the Job, ' Ph.D. Thesis. Massachusetts Institute of Technology, August. National Technical Information Service No. DLMA 91-25-75-17-11.

38. Karasek, R.A., 1979, 'Job Demands, Job Decision Latitude, and Mental Strain: Implications for Job Redesign," Administrative Science Quarterly, 24, pp. 28-306, June.

39. Karasek, R.A., Baker, D., Marxer, F., Ahlbom, A., and Theorel1, T., 1981, 'Job Decision Latitude, Job Demands and Cardiovascular Disease: A Prospective Study of Swedish Men,' American Journal of Public Health, 71, pp. 694-705, July.

40. Karasek, R.A., Triantis, K., Chaudry, S., 1982a, 'Coworker and Supervisor Support as Moderators of Associations Between Task Characteristics and Mental Strain,' Journal of Occupational Behavior, 3, pp. $181-200$.

41. Karasek, R.A., Lindell, J., and Gardell, B., 1982b, 'Patterns of Health in Relation to Work and Nonwork Stressor for Male and Female Swedish White Collar Workers,' Swedish Center for Working Life, Stockholm, Sweden.

42. Kasl, S.V., 1979, Epidemiological Contributions to the Study of Work Stress. in: Cooper C. and Payne R. (Eds.) : Stress at Work. New York: John Wiley and Sons, pp. 3-50.

43. Katzel1, R. A., P. Beinstock and P. Faerstein, 1977, A Guide to Worker Productivity Experiments in the United States, New York: New York University Press

44. Kennedy, T.G.S. and R. Edmonds, 1974, 'An Examination of Training Problems with Naive Computer Users,' Proc. Eur. computing congress (Eurocomp74) (May), pp. 411-425.

45. Kling, R., 1978, 'The Impacts of Computing on the Work of Managers, Data Analysts, and Clerks, ' working Paper, Public Policy Research Organization, University of California at Irvine, Irvine, CA.

46. Kraemer, K., Dutton, W. and Northrop, A., 1981, The Management of Information Systems, Columbia University Press, New York.

47. Langner, I. and Michaels, S., 1963, Life Stress and Mental Health, Free Press, New York. 
48. LaRocco, J.M., House, J.S. and French, J.R.P., 1980, 'Social Support, Occupational Stress, and Health,' Journal of Health and Social Behavior, 21, pp. 202-216.

49. Lazarus, R., 1966, Psychological Stress and the Coping Process, New York: McGraw-Hill.

50. Mann, F. and L. Williams, 1960, 'Observations on the Dynamics of a Change to Electronic Data Processing Equipment,' ASQ, 5, pp. 217-276.

51. Martin, J., 1973, Design of Man-Computer Dialogues, Prentice-Hall, Englewood Cliffs.

52. McGrath, S.E., 1976, 'A Conceptual Formulation for Research in Stress,' in McGrath, J.E. ed. Social and Psychological Factors in Stress, Holt, Rinehart, Winston, New York, pp. 10-21.

53. McKinsey and Company, 1963, 'Your Computer,' New York.

54. Miller, L., 1981, 'Natural Language Programming: Styles, Strategies, and Contrasts,' IBM Systems Journal, 20 , 2, pp. 184-215.

55. Moray, N., ed. 1979, Mental Workload, Plenum Press, New York.

56. Mumfurd, E. and M. Weir, 1979, Computer Systems in Work Design $=$ the ETHICS Method, John Wiley and Sons, New York. -

57. Reisner, P., 1981, 'Human Factors Studies of Database Query Languages: A Survey and Assessment,' Computing Surveys 13, 1, pp. 13-31.

58. Rouse, R., 1981, 'Human-Computer Interaction in the Control of Dynamic Systems,' ACM Computing Surveys, 13, 1, pp. 71-99.

59. Salvendy, G., 1981, 'Machine Pacing, an Overview,' Proceedings: International Conference on Machine Pacing and occupational stress, Taylor and Francis London.

60. Selye, H., 1973, 'The Evaluation of the Stress Concept,' American Scientist, 61, pp. 692-699.

61. Sheil, B., 1981, 'The Psychological Study of Programming,' ACM Computing Serveys, 13, 1, pp. 101-120.

62. Shepard, J., 1971, Automation and Alienation: A Study of Office and Factory Workers, The MIT Press, Cambridge, Mass. 
63. Shneiderman, B., 1980a, 'Hardware Options, Evaluation Metrics, and a Design Sequence for Interactive Information Systems,' Information and Management, 3, pp. 3-18.

64. Shneiderman, B., 1980b, Software Psychology, Winthrop, Cambridge, MA.

65. Shneiderman, B., 1982, 'System Message Design: Guidelines and Experimental Results,' in A. Badre and B. Shneiderman, eds. Directions in Human-Computer Interaction, Ablex, New York.

66. Siegal, A. and Wolf, J., 1969, Man-Machine Simulation Models, Wiley, New York.

67. Smith, M., Cohen, B., Stammerjohn, B., Happ, A., 1981, 'An Investigation of Health Complaints and Job Stress in Video Display Operations,' Human Factors, August.

68. Sperandio, J., 1971, 'Variation of Operator's Strategies and Regulating Effects on Workload, ' Ergonomics, 14, 5, pp. 571-577.

69. Trist, E. and Bamforth, K., 1951, 'Some Social and Psychological Consequences of the Longwall Method of Coal Getting, Human Relations, pp. 3-38.

70. Turner, J.A., 1980, 'Computers in Bank Clerical Functions: Implications for Productivity and the Quality of Life,' Ph.D. dissertation, Columbia University, May.

71. Turner, J.A., 1981a 'Achieving Concensus on Systems Requirements,' S.O.S., 1, 3, pp. 141-148.

72. Turner, J. A., 1982, 'Firm Size, Performance, and Computer Use, proceedings of the Third International Conference on Information Systems, Ann Arbor, MI, December, p. 109-20.

73. Turner, J. A., M. Jarke, E. Stohr, Y. Vassiliou, and N. White, 1982, 'Using Restricted Natural Language for Data Retrieval: A Plan for Field Evaluation,' NYU User Interface Symposium, New York, in Y. Vassiliou, ed. User Interfaces, Iblex, New York (forthcoming).

74. Umbers, I, 1979, 'Models of the Process Operator,' International Journal of Man-Machine Studies, 11, pp. 263-284.

75. Welford, A., Brown, A., and Gabb, J., 1950, 'Two Experiments on Fatigue as Affecting Skilled Performance in Civilian Air Crews,' British Journal of Psychology, 
40, pp. 195-211.

76. Welford, A., 1976, Skilled Performance: Perceptual and Motor skills, Scott-Foresman and Co. Glenview, Illiñois.

77. Zaret, M., 1980, 'Cataracts Following Use of Cathode Ray Tube Displays, ' Proceedings of International. Symposium of Electromagnetic Waves and Biology, France, June.

78. Ziegarnik, B., 1927, 'Das Behalten erledigter unerliedigter Handlungen,' Psychologische Forschung, 9, pp. 1-85.

79. Zubek, J., 1964, Effects of Prolonged Sensory and Perceptual Deprivation, British Medical Bulletin, 20,1 , pp. 38-42. 

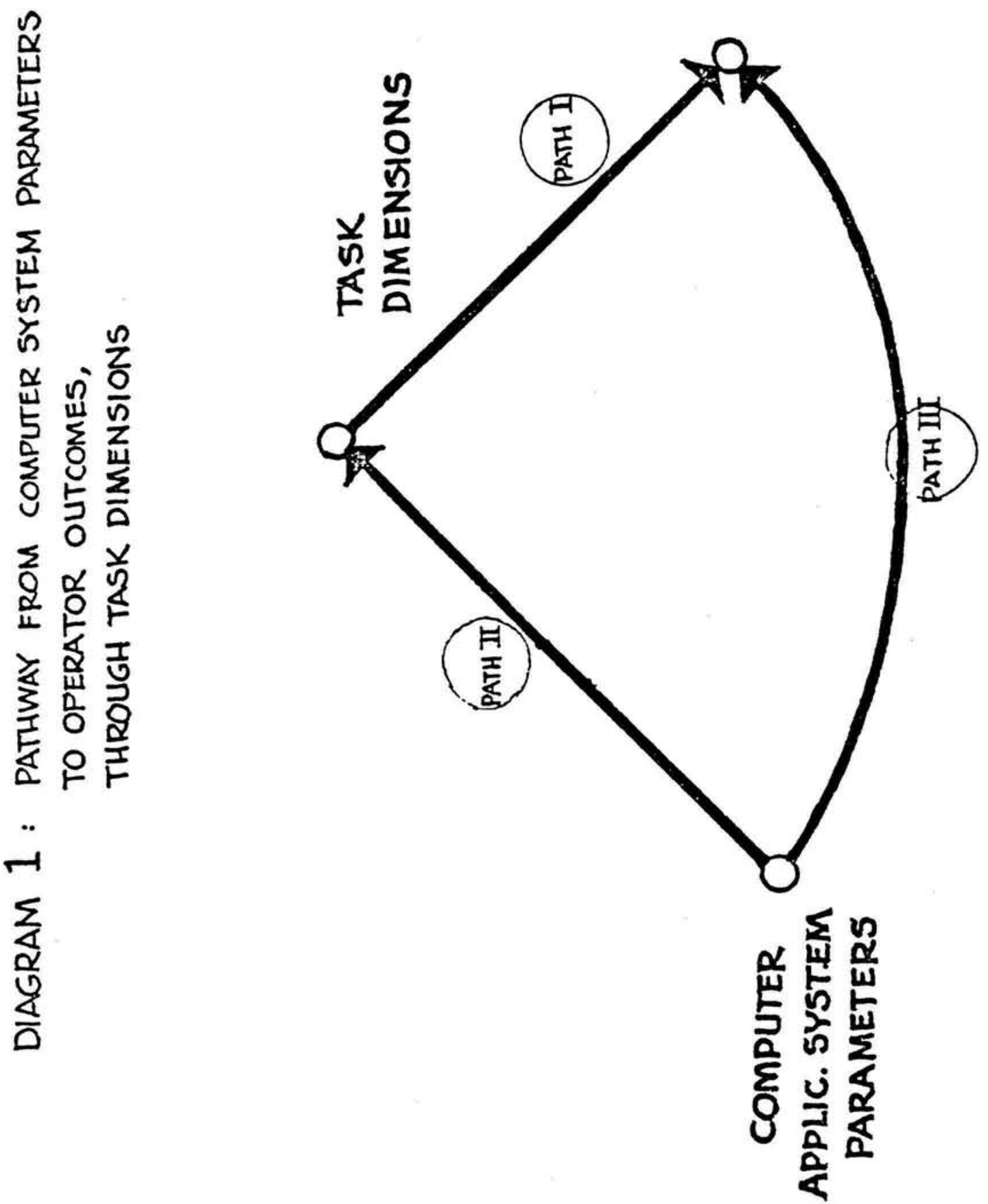

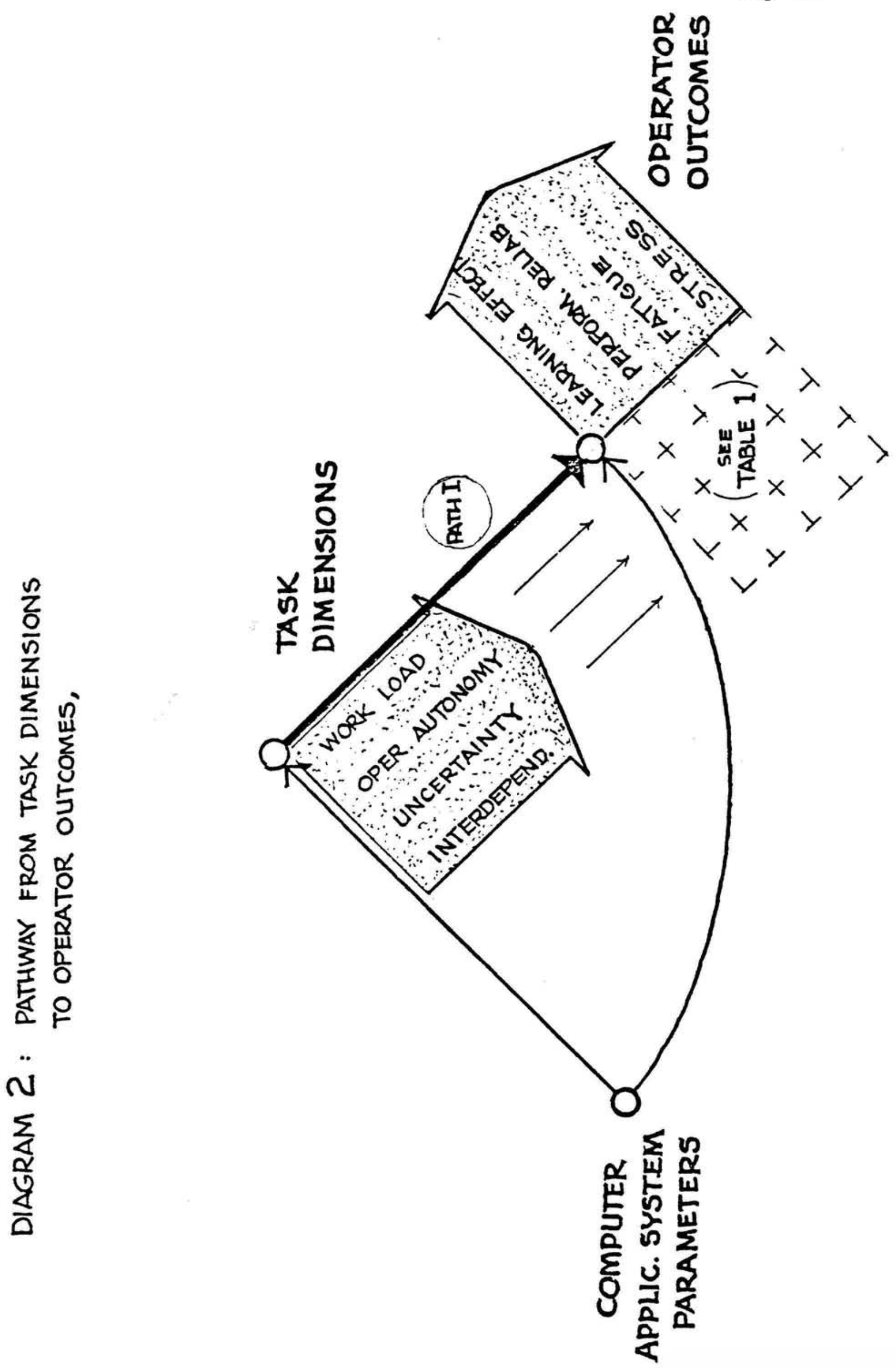


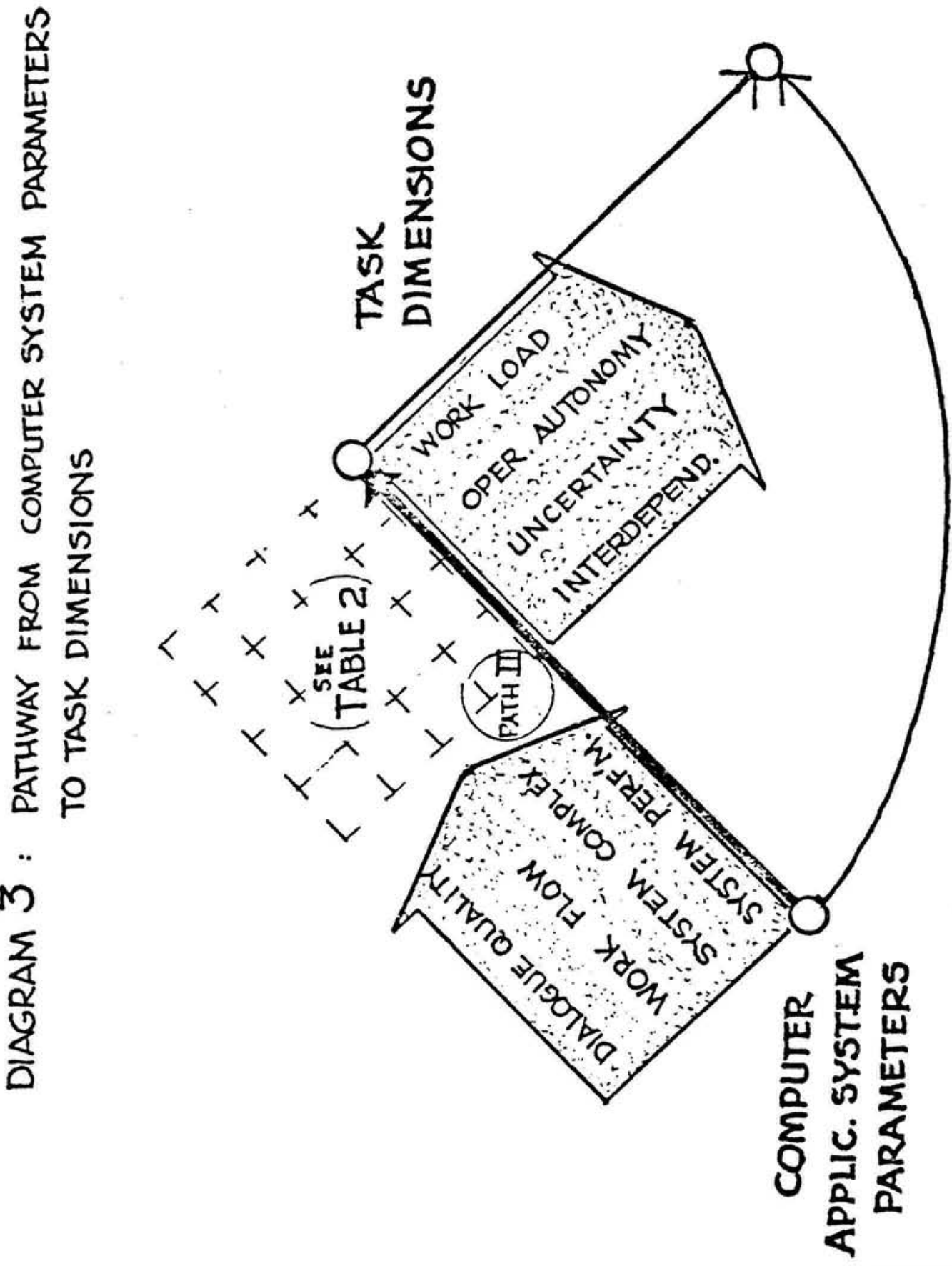


Table 1: Summarized*Associations Between

Task Characteristics and Mieasures

OF OPERATOR EFFECTIVENESS AND

WELL-BEING

Operator Effectiveness and Well-being

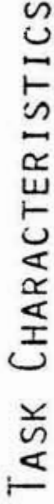
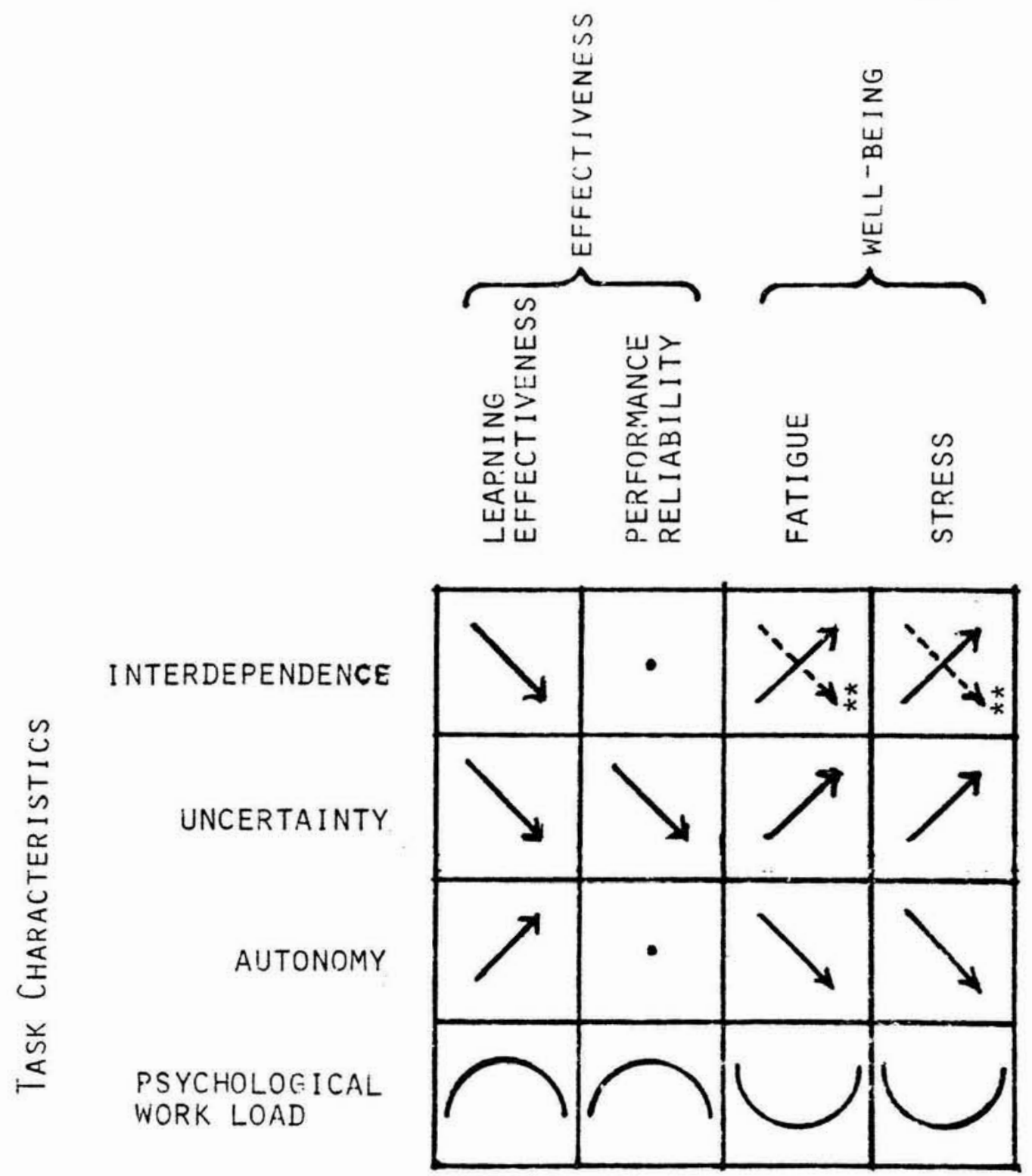

- No relationship

Effects increase as task parameter increases.

Effects decrease as task parameter increases.

$\mathcal{U} \mathrm{U}$-shaped, curvilinear association between effects and task parameter.

$\therefore *$ Negative association for forms of voluntary interdependence.

*Evidence is presented in Section 2 and summarized in numerous articles. This summary, while representstivo of the majority of evidence, hardly be said to be unanimo 
Table 2: Hypothesized Relationships between Computer System Parameters and Task Dimensions
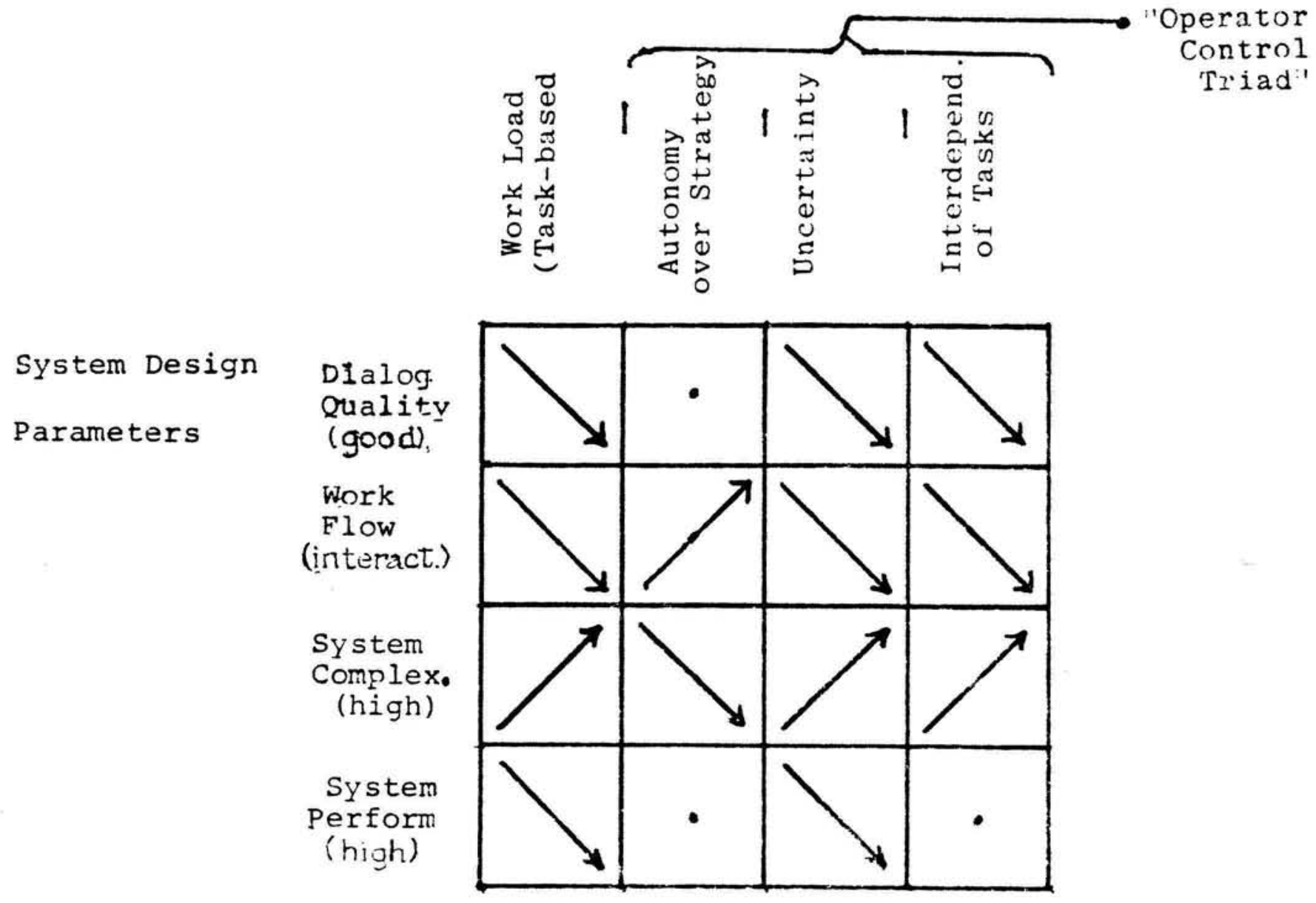

Composite Undiff. System (high usage)

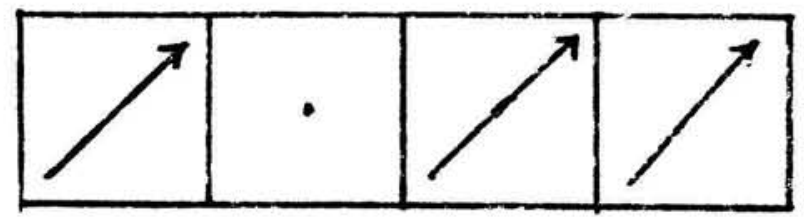

Hypothesized Relationships - (scale direction shown in varentheses)

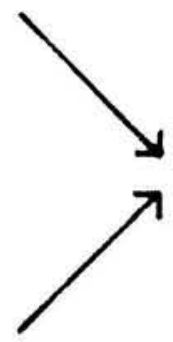

Task dimension decreases

with the parameter

Task dimension increases

with the parameter

- No hypothesized relationship 
Table 3: Associations Between Operator Well-Being Task Characteristics and Computer Use Intensity

\begin{tabular}{|c|c|c|c|c|c|c|}
\hline CALE & $\begin{array}{l}\text { Computer } \\
\text { Use } \\
\text { Intensity }\end{array}$ & $\begin{array}{l}\text { Operator } \\
\text { Work } \\
\text { Load }\end{array}$ & $\begin{array}{l}\text { Operator } \\
\text { Decision } \\
\text { Making } \\
\text { Latitude }\end{array}$ & $\begin{array}{c}\text { Task } \\
\text { Interdependence }\end{array}$ & $\begin{array}{l}\text { Mental } \\
\text { Strain } \\
\text { Symptoms }\end{array}$ & $\begin{array}{l}\text { Job } \\
\text { Satisfaction }\end{array}$ \\
\hline
\end{tabular}

\author{
Computer \\ Use \\ Intensity
}

Operator Work Load

\section{Operator Decision Making Latitude}

Task Interdependence

\section{Mental Strain} Symptoms

Job Satisfaction

$-.01--.08$

$.25^{*}$
$.11^{*}$

$$
-.02
$$$$
-.31^{*}
$$

Pearson Product Moment Correlation Coefficients, from a study of 1001 mortgage loan servicing clerks, showing the relationship between task environment, strain, satisfaction, and computer use intensity scales (adapted from Turner, 1980).

* - Significant at the 0.001 level or better. 
Table 4: Comparison Between Task Characteristics of Operators Using Computer Systems and a Control Group.

\begin{tabular}{|c|c|c|c|c|}
\hline $\begin{array}{l}\text { Work } \\
\text { Pressure } 1\end{array}$ & $\begin{array}{c}\text { Work Load } \\
\text { Dissatisfaction } 2\end{array}$ & $\begin{array}{r}\text { Quantitative } \\
\text { Workload-Q2 }\end{array}$ & Autonomy 1 & $\begin{array}{l}\text { Control by } \\
\text { Supervisor } 1\end{array}$ \\
\hline
\end{tabular}

Clerical Workers

Using Computer Systems

3.4

3.2

4.0

1.1

3.0

Clerical Control

Group

2.4

2.4

3.6

1.8

2.7

Scale Norms

1.8

2.1

2.7

2.3

Significant Test Level (ANOVA)

.01

.01

.01

.01

.01

Mean scale responses for CRT operators and controls at five work groups (adapted from Smith et al., 1981)

$\mathrm{N}=$ About $150 \mathrm{CRT}$ operators and 150 controls

Source of Measures:

1 = Work Environment Scale - FORM - S (Insel and Moos, 1974)

2 = Job Demands and Norker Health scales (Capland et al., 1975) 